\title{
Processos Individuais De Apropriação Tecnológica E Pedagógica: Uma Análise De Narrativas Pessoais
}

\author{
Erancismara Fernandes Guerra \\ Carlito A.S. Balbino \\ Andrea de Castro Araujo Silva dos Santos
}

\section{RESUMO}

Este trabalho busca entender os motivos pelos quais a apropriação tecnológica no ensino demora efetivar-se. Para tanto, foram coletados depoimentos de profissionais da educação sobre o seu conhecimento tecnológico, a forma de aquisição e as tecnologias frequentemente usadas em suas práticas pedagógicas, bem como o que tem sido feito para aprimorar seus conhecimentos. Percebeu-se que esses profissionais ainda não apresentam o nível apropriado de familiaridade e de domínio dos recursos tecnológicos, o que dificulta acompanhar a expectativa do aluno atual, membro de uma geração da era digital em uma sociedade bastante que se modifica a todo o momento em detrimento da velocidade das inovações tecnológicas. As dificuldades mais apontadas foram: falta de tempo; pouco contato com as tecnologias, o que gera receio no uso de novos aplicativos; falta de recursos na escola e falta de cursos de capacitação para o uso das tecnologias nas aulas. E, apesar disso, percebeu-se, por esta pesquisa, haver a necessidade e a vontade de vencer esse desafio educacional, tendo em vista a concepção de que a apropriação acerca do conhecimento das tecnologias digitais da informação e da comunicação é essencial para o trabalho docente, assim como uma exigência da sociedade.

Doutorado em Demografia pelo Centro de Desenvolvimento e Planejamento Regional CEDEPLAR - da Universidade Federal de Minas Gerais - UFMG.

Docente do Instituto Federla de Minas Gerais.

\section{Doutorado}

em Ciências

Ambientais

(Meio Ambiente, Mudanças Globais) pela Universidade do Estado do Rio

de Janeiro. 


\begin{abstract}
This research seeks to understand the reasons why the technological appropriation in teaching delay in effect. Therefore, we collect testimonies from education professionals on their technological knowledge, the manner of acquisition and technology often used in their teaching practices, as well as what has been done to improve their knowledge. It was noticed that these professionals still do not have the appropriate level of familiarity and mastery of technological resources. What makes it difficult to follow the expectations of the current student member of the generation of the digital age in a society that is changing all the time to the detriment of the speed of technological innovations. The difficulties mentioned most frequently were: lack of time; little contact with the technologies, which generates fear in the use of new applications; lack of resources in school and lack of training courses for the use of technology in the classroom. And yet, we find, for this research, there is the need and the wish to win this educational challenge, given the view that the appropriation about knowledge of digital technologies of information and communication is essential for teaching as well as a requirement of society.
\end{abstract}

Keywords: Education, Digital technologies of information and communication. Technological and pedagogical appropriation.

\title{
1 INTRODUÇÃO
}

Atualmente, percebe-se que a preocupação das políticas educacionais se volta ao hiato existente entre o que se tem e o que se espera em torno da apropriação tecnológica e de suas diferentes formas de utilização. Essa inquietação é generalizada e parte tanto dos profissionais das instituições de ensino, quanto dos próprios alunos que têm plena consciência das exigências da sociedade atual.

Dessa forma, questiona-se: qual o nível de apropriação tecnológica do profissional da educação? Esse profissional coloca em prática aquilo que aprendeu? Quais as principais dificuldades enfrentadas para superar os desafios da apropriação tecnológica na escola? Tendo em vista tais questões, pretende-se investigar se as práticas pedagógicas usadas estão em consonância com a evolução tecnológica, bem 
como avaliar a adequação do ensino-aprendizagem oferecido pelas diversas instituições educacionais, o que permite propor ajustes às diretrizes adotadas no ensino em relação às exigências de uma sociedade em transformação.

Este trabalho, portanto, fundamenta-se na análise de narrativas pessoais de diversos profissionais da educação sobre seu conhecimento e os níveis de apropriação tecnológicos direcionados às práticas pedagógicas. Por meio dessas narrativas, como pontua Reis (2008), os docentes e os demais profissionais têm a possibilidade de contar suas histórias, de avaliar seu desempenho, de refletir sobre as experiências obtidas na trajetória profissional e de se sentir motivado, alterando, dessa maneira, as formas de pensar suas práticas de ensino e aprendizagem, e mantendo uma atitude crítica de seu desempenho profissional, além de permitir a reconstrução de suas próprias experiências.

\section{REVISÃO BIBLIOGRÁFICA}

A concepção de pessoa, que surgiu com o fim da Idade Média e o início da era industrial, baseava-se na ideia de que o indivíduo-sujeito era alguém autocentrado, uno, absolutamente racional, consciente e capaz de agir sobre a realidade. Moura (2008, p.69) ainda afirma:

indivíduo e mundo se completam e se amparam como referenciais estáveis que conferem segurança psicológica e social ao processo de inserção do sujeito no mundo das fábricas e das cidades, da produção e do consumo de massa, da comunicação de massa.

Kampff (2006, p.15), quando refere-se a tempos de mudança, deixa claro que é bastante comum ouvir a afirmação de que "vive-se na sociedade da informação, na era digital", porém coloca em questionamento se, no mundo globalizado, todos se encontram na mesma era e quais são as características desejadas para que os homens de seu tempo possam exercer plenamente a cidadania. Segundo o autor, a fase da contemporaneidade é marcada pelo surgimento da rede de computadores e de avanços tecnológicos em massa, em que o indivíduo é, ao mesmo tempo, produtor e consumidor da informação, com capacidades para ter acesso, interagir, modificar, divulgar de forma personalizada de acordo com seus interesses, percorrer um mundo globalizado com capacidades de interação em tempo real, onde o que vale é a velocidade cada vez maior da informação e da divulgação. 
No entanto, ao abordar a criação de redes de conhecimento, Almeida (2001) deixa claro que fazer parte da sociedade da informação não se restringe a ter acesso à Tecnologia da Informação e da Comunicação (TIC), mas ao fato de saber usar essa tecnologia de forma mais abrangente, de apropriar-se dela, de modo que cada indivíduo possa selecionar informações que o conduza a resolver problemas, a compreender o mundo que o cerca, a permitir que seja atuante e transformador de seu contexto. A rede de conhecimento deve permitir a democratização social e favorecer o posicionamento crítico frente às questões de desenvolvimento humano, social e cultural de forma a promover uma sociedade mais justa e igualitária.

Dessa maneira, segundo Kenski (1997), não basta que o sujeito adquira conhecimentos operacionais para interagir com as tecnologias, uma vez que as novas tecnologias refletem de forma ampliada sobre a natureza do que é ciência, do que é conhecimento, exigindo uma reflexão mais profunda do saber e das novas formas de ensinar e aprender.

Para Rosa (2013), os professores, de um modo geral, apresentam dificuldades de compreender e utilizar os recursos tecnológicos na prática docente, tornando-os parte de seus trabalhos. Aponta a autora que não basta apenas simples domínio instrumental, é necessário que o professor conheça as potencialidades que cada tecnologia pode proporcionar de acordo com a metodologia a ser utilizada, de modo a direcionar o trabalho docente, proporcionando novos caminhos, objetivos e formas de interação com os alunos. Rosa (2013), ao mencionar Peixoto, Brandão e Santos (apud ROSA, 2013, p.220) destaca que:

o sentido mais amplo da tecnologia não se refere só à sua utilidade funcional. É preciso ter em mente que a tecnologia ao servir a determinada prática pedagógica, os sujeitos envolvidos experimentem a tecnologia de modo a incorporá-la. Isso significa que tanto professores e alunos precisam se apropriar das TIC de forma que sua utilização e a construção do conhecimento se efetuem como co-criação e não simplesmente como transmissão. Para tanto, o docente precisa atuar com base em um novo paradigma, não mais como apenas transmissor de informação, mas na criação de situações de aprendizagem nas quais o aluno realiza atividades e constrói o seu conhecimento.

Ao discorrer sobre os impactos das novas tecnologias na prática docente, Kenski (1997 p.68) deixa claro que compreender este novo mundo exige uma nova lógica e uma nova estrutura. A apreensão do conhecimento como possibilidade didática exige, também, a orientação da prática docente para uma nova cultura, uma nova percepção; não mais na forma linear de apresentar e desenvolver o conteúdo a 
ser ensinado, mas baseada na exploração de novos tipos de raciocínio que possibilitem reflexões e relações com outras áreas do conhecimento aparentemente distintas.

Porém, Duarte e Augusto (2006 2007) ressaltam que, na atualidade, o trabalho docente se configura com acúmulo de atividades devido às contingências situacionais e emergenciais dos alunos e da escola. O trabalho coletivo não acontece como deveria, porque exige planejamento e interação com outros profissionais da educação, comunidade, pais e alunos. Tais atividades extrapolam a vida profissional desses indivíduos e acabam invadindo o horário da vida pessoal. Outro aspecto apontado por Duarte e Augusto (2007) refere-se ao confronto entre autonomia e avaliação, pois ao mesmo tempo em que se prega autonomia do professor e o poder de decisão da escola, criam-se múltiplas avaliações como instrumentos de controle das políticas educacionais.

A hora-atividade é uma conquista da luta dos professores para se dedicarem a pesquisas, planejamento e avaliação do ensino-aprendizagem que exige tempos diferenciados para sua organização. Ressalta ainda que, apesar de ser consagrada na legislação, ainda existe uma distância entre o que é prescrito na lei e a efetividade desse direito.

Sica e Bortolini (2007) afirmam que os professores da educação básica carregam sobre si uma grande carga de responsabilidades na construção de conhecimentos das crianças e adolescentes e que, mediante as exigências contemporâneas do ensino-aprendizagem, há sempre a necessidade de formação ou reciclagem. Nessas exigências, encontra-se a inclusão digital, uma vez que a informática é uma das ferramentas mais utilizadas na sociedade da informação e são fundamentais para que os alunos, junto dos professores, possam compor essa sociedade do conhecimento.

Almeida (2005), refereindo-se sobre a rede, destaca que o conhecimento se faz a partir da interação do homem com o meio e com os objetos nele existentes. Por meio dessa interação, ele atua sobre os objetos, identifica, retira informações e os incorpora à sua rede de forma a transformar o meio e ser transformado por ele.

Dessa forma, o professor está sempre envolvido com os processos de construção do conhecimento e de avaliação da própria existência, uma vez que segundo Sica (2007, p.25) "o ensino-aprendizagem implica tanto em saber quanto a dor de não saber". Essa angústia também leva a novos espaços e à busca de novos conhecimentos. E, para que haja apropriação de saberes tanto na informática quanto 
em qualquer outra área de formação, são necessárias disponibilidade, perseverança, criatividade e autonomia.

Diante da problematização em torno do trabalho docente, surgem muitos modelos e propostas ultrapassados de como o professor deve desenvolver sua prática pedagógica. Dessa forma, Alonso (2014) questiona se é correto seguir formando professores em modelos hierárquicos e disciplinares, sabendo que deverão ensinar e aprender em rede. Desse modo, a apropriação das tecnologias deve preparar o professor para viver mudanças significativas na prática docente que essa inovação trouxe à sociedade.

Portanto, compreendendo que não existe nenhuma receita pronta para o trabalho pedagógico, Simões e Silva (2013) propõem uma reflexão sobre as dimensões do trabalho, da ciência, da tecnologia e da cultura como fundamento da formação humana. Segundo os autores, "[é] na sua reflexão e reelaboração da concepção da educação e da formação humana que o educador pode atribuir significado para sua prática pedagógica" (SIMÕES; SILVA, 2013, p.18).

\section{MATERIAL E MÉTODO}

O método empregado neste trabalho constitui-se de análise de conteúdo da reflexão proposta a profissionais da educação às seguintes perguntas: o que tenho feito para investir na qualificação profissional com uso de tecnologias? Quais as principais dificuldades enfrentadas para superar tais desafios? Esse processo de apropriação tecnológica é contínuo? Estou de acordo com o esperado pelos meus alunos? O que sei fazer bem? Como aprendi? Como sei que aprendi? Coloco em prática aquilo que aprendi? O que me impede de aprimorar mais?

Tais questões constituem-se de uma atividade proposta durante o curso de especialização em Educação na Cultura Digital, oferecida pela Universidade Federal de Ouro Preto, no qual os respectivos cursistas compõem o público alvo que conta com professores, diretores, vice-diretores, pedagogos de escolas públicas estaduais de Minas Gerais, bem como técnicos especialistas em tecnologias da informação e da computação, que atendem a essas escolas. Essa especialização objetiva fornecer capacitação teórica e prática para a elaboração de planos de ação coletiva dentro das escolas, com o intuito de promover a apropriação de diversas tecnologias digitais ao processo de ensino e aprendizagem. Assim, a escolha desse público justifica-se pelos seus interesse e afinidade com a temática abordada, a 
Dividida em turmas, a especialização conta inicialmente com 175 cursistas, de 25 escolas distintas, chegando a sua última etapa com cerca de 60 participantes. Visto o acesso limitado às informações de uma única turma, a amostra analisada constitui-se somente de 49 cursistas, distribuídos em 7 escolas, dos quais apenas 17 responderam às questões propostas.

\section{RESULTADOS E DISCUSSÕES}

Pode-se perceber, por meio dos depoimentos, que os desafios enfrentados pelos profissionais da educação estão relacionados ao fato de ainda não apresentarem o nível apropriado de familiaridade e de domínio dos recursos tecnológicos, o que dificulta acompanhar a expectativa do aluno atual, membro de uma geração da era digital e tecnológica em uma sociedade que se modifica a todo o momento em detrimento da velocidade da inovação dessa tecnologia.

Grande parte dos profissionais ouvidos admite que faz uso do computador para digitação de textos, impressão de provas, entretenimento e redes sociais, cujo conhecimento foi adquirido por meio de poucas horas de capacitação ou por curiosidade de manusear os aplicativos no computador. Uma pequena parte desses profissionais elabora trabalhos que utilizam slides, planilhas eletrônicas, vídeo-aulas e/ou aplicativos diversos.

A principal característica encontrada nas narrativas ouvidas foi o desejo de mudança, tanto dos profissionais que buscam capacitação nos conhecimentos que envolvem as Tecnologias Digitais da Informação e da Comunicação (TDIC) quanto dos que já possuem um nível mais elevado de apropriação dessas tecnologias, para aprender novas formas de ensinar e capacitar outras pessoas.

É possível notar que as práticas docentes não exigiam muito o uso das TDIC por ainda estarem atreladas às práticas pedagógicas tradicionais com uso frequente do livro didático e da lousa, justificando-se inclusive pela falta de infraestrutura e apoio tecnológico e pelo desconhecimento de como adequar o planejamento de ensino aos recursos oferecidos pela tecnologia. Outro motivo apontado é a dificuldade pessoal de adaptação aos recursos tecnológicos, que fica clara na expressão de um professor: "em relação à minha experiência tecnológica, confesso que sou uma preguiçosa digital, talvez por não ter paciência de ficar horas no computador. Já fiz alguns cursos básicos, mas se não anotar o passo a passo de alguns aplicativos que uso, acabo esquecendo". 
Contudo, a persistência e a interação com os colegas compensam a falta de conhecimento e apropriação das tecnologias, como se vê na seguinte fala: "sou lenta. Se puderem me ajudar... com a teimosia eu acabo ampliando o conhecimento e adquirindo um pouquinho mais".

Conhecimentos básicos e níveis mínimos de apropriação de alguma tecnologia não são suficientes para o desenvolvimento do ensino atual. As dificuldades de se trabalhar com as tecnologias na prática docente são agravadas pela falta de infra-estrutura das escolas, deixando grandes expectativas quanto à aprendizagem.

\begin{abstract}
A minha trajetória é o desejo de aprender e colocar em prática as tantas ideias que surgem e as reais possibilidades de colocar em prática devido a diversos fatores como o teórico ainda se encontra com certo distanciamento da prática; os recursos são muito precários e não atendem a um determinado número de alunos que temos em média na sala de aula. Quando ousamos levá-los ao laboratório de informática, os computadores não funcionam, a internet é lenta e trava o tempo todo, e os alunos acabam frustrados.
\end{abstract}

É notório o reconhecimento da necessidade e da vontade de aprender, como visto em: "tenho dificuldades com boa parte dos aplicativos, estou aprendendo agora, principalmente com a experiência de outros colegas cursistas, cujas práticas pretendo incluir em meu trabalho" (informação verbal). E é por meio de formação continuada que os conhecimentos se ampliam, pois permitem o compartilhamento de ideias e o processo de interação social - fatores relevantes para a evolução do processo de ensino e aprendizagem.

Os depoimentos ainda revelam os receios e a ansiedade diante das dificuldades enfrentadas no processo de apropriação das tecnologias, bem como a falta de tempo para se dedicar de forma mais efetiva às atividades de aprimoramento. Ressalta-se que, apesar da euforia com as possibilidades que a tecnologia oferece, é comum a sensação de impotência devido à falta de habilidade no seu uso.

\footnotetext{
Aliar as tecnologias a serviço dos conteúdos e da aprendizagem não é tarefa fácil e, realizando as atividades do curso, minha apreensão às vezes aumenta porque as dificuldades encontradas têm sido grande, não sei se pelo fator tempo, que é muito pouco, ou se porque trabalhar com todas essas novidades é mesmo difícil.
}

Entretanto, um profissional afirma sentir-se bastante envolvido com a cultura digital na educação, uma vez que procura desenvolver muitas atividades usando as TDIC, de acordo com as possibilidades da escola. Contudo, surpreendentemente, diz que não desfaz da maneira tradicional de ensinar. Apesar de admitir familiaridade 
com as tecnologias e sentir-se pioneiro nesse quesito, promovendo inclusive maior interação entre os colegas e os alunos, ele percebeu que essa prática era desvinculada dos assuntos trabalhados em sala de aula. Ressaltando, ainda, preferência ao usar as tecnologias com alunos selecionados, a fim de evitar situações estressantes.

Meu grande desafio é me apropriar bem das tecnologias, usando-as pedagogicamente, ou seja, estou no processo da introdução das TDIC na educação. Por isso estou buscando conhecer mais, praticar mais e alimento expectativa alta de melhorar a minha prática, cursando essa pósgraduação.

Por fim, percebe-se que o momento exige uma reformulação das práticas devido a uma configuração social que é pautada no modelo digital de pensar, criar, produzir, comunicar, aprender e dividir. Por isso, alguns consideram que seja preciso avançar muito, mesmo já conseguindo elaborar algumas atividades escolares com o uso das TDIC.

\section{CONCLUSÕES}

De acordo com as narrativas apresentadas, os conhecimentos relatados limitam-se a habilidades de digitação com o uso de editores de textos e planilhas eletrônicas, de produção de slides e pesquisas na internet. Em geral, foi possível perceber que a teoria ainda se encontra aquém da prática por diversos fatores que dificultam o trabalho pedagógico em relação ao uso efetivo dos recursos tecnológicos.

Falta de infraestrutura nas escolas, material insuficiente para atender a demanda; escassez de cursos de capacitação voltados para o planejamento e a prática pedagógica coerentes com o conhecimento prévio; falta de tempo; internet lenta; indisciplina; receio de não corresponder às expectativas dos alunos que já possuem bastante familiaridade com as tecnologias e a carência de uma política educacional que realmente promova a apropriação e a prática tecnológica são fatos recorrentes nas falas dos profissionais da educação.

Dessa forma, cabe ressaltar que a apropriação dos recursos tecnológicos não se restringe ao uso do computador, usado em massa para o desenvolvimento de tarefas isoladas do planejamento pedagógico, mas ao domínio de seus aplicativos e de suas potencialidades para um fim em que se possam visualizar objetivos, metodologia e avaliação dos resultados.

Por mais que haja curiosidade para aprender e, consequentemente, vencer os obstáculos, constata-se que muitos docentes tiveram pouca ou nenhuma instrução 
sobre as ferramentas modernas na formação acadêmica. Desse modo, os relatos deixam clara a necessidade de que o docente tem de se localizar e de se posicionar nesse novo mundo veloz e inovador.

Propõem-se as seguintes medidas como ajustes às diretrizes atuais do ensino:

a) Desenvolvimento de projetos similares ao Projeto UCA (Um Computador por Aluno). A aquisição de notebooks em número suficiente para o uso individual de pelo menos uma turma, o que tornaria o processo de ensino e aprendizagem mais eficaz e organizado, pois permitiria agendar seu uso em sala para qualquer disciplina;

b) Adequação da jornada de trabalho e do calendário escolar contemplando tempo para a capacitação, pois os cursos de formação continuada são, muitas vezes, oferecidos durante os horários de aula e a escola não dispõe de profissionais auxiliares;

c) Inclusão de disciplinas práticas para o uso das tecnologias na formação acadêmica e nos estudos de formação continuada, principalmente do Pacto Nacional, visando ao fortalecimento da educação básica, com didáticas e metodologias voltadas para as especificidades de cada disciplina.

Por fim, o direito a uma apropriação tecnológica eficaz deve ser garantido e fazer parte do currículo de todo educador. A escola, por ser formadora de cidadãos, não pode ficar distante dessas expectativas, muito menos alheia a essa realidade imposta pela era digital.

\section{REFERÊNCIAS}

ALMEIDA, Maria Elizabeth Bianconcini de. Tecnologia na escola: criação de redes de conhecimentos. In: ALMEIDA, Maria Elizabeth Bianconcini de; MORAN, José Manoel. (Org.). Integração das tecnologias na educação. Brasília: Ministério da Educação, SEED, 2005.

ALONSO, K. M. Aprender e ensinar em tempos de Cultura Digital. Revista de Educação a Distância, Porto Alegre, v. 1, n. 1, p. 152-168, 2014.

DUARTE, Adriana; AUGUSTO, Maria Helena. Trabalho Docente: configurações atuais e concepções. In: SIMPÓSIO BRASILEIRO DE POLÍTICA E ADMINISTRAÇÃO DA EDUCAÇÃO, 23., 2007. Porto Alegre. Anais...Porto Alegre: ANPAE, 2007. 
KAMPFF, Adriana Justin Cerveira. Tecnologia da informação e comunicação na educação. Curitiba: IESDE Brasil S.A. 2006.

KENSKI, Vani Moreira. Novas tecnologias: O redimensionamento do espaço e do tempo e os impactos no trabalho docente. In: REUNIÃO ANUAL DA ANPED, 20, 1997. Caxambu. Anais. Caxambu: ANPED, 1997.

MOURA, Paulo G. M. de. Sociedade e contemporaneidade. Curitiba: IESDE Brasil S.A., 2008.

PEIXOTO, Maurício de Abreu Pinto; BRANDÃO, Marcos Antônio Gomes; SANTOS, Gladis dos. Metacognição e tecnologia educacional simbólica. Revista Brasileira de Educação Médica, v. 31, n. 1, p. 67-80, 2007.

REIS, Pedro. As narrativas na formação de professores e na investigação em educação. NUANCES: estudos sobre Educação, v. 15, n. 16, p. 17p.-34, 2008.

ROSA, Rosemar. Trabalho docente: dificuldades apontadas pelos professores no uso das tecnologias. Revista Encontro de Pesquisa em Educação, Uberaba, v. 1, n.1, p. 214-227, 2013.

SICA, Fernando Cortez; BORTOLINI, Neide das Graças de Sousa. Educação e informática: um diálogo essencial. Ouro Preto: Universidade Federal de Ouro Preto, 2007.

SIMÕES, Carlos Artexes; SILVA, Monica Ribeiro da. O currículo do ensino médio, seu sujeito e o desafio da formação humana integral: formação de professores do ensino médio. Etapa I - caderno III. Curitiba: UFPR/Setor de Educação. 2013.

VALENTE, J. A.; ALMEIDA, M. E. B. de. Narrativas digitais e o estudo de contextos de aprendizagem. Revista de Educação a Distância, v. 1, n. 1, 2014. 